\title{
El caso de los niños lebensborn. Análisis del proyecto de eugenesia nazi desde el paradigma de la biopolítica.
}

\author{
Leandro Emmanuel Espíndola \\ Estudiante del Profesorado en Filosofía \\ Universidad Nacional del Nordeste \\ Leanfilo@hotmail.com
}

\section{Resumen}

El presente artículo pretende analizar el proyecto de eugenesia nazi desde el paradigma de la biopolítica, y determinar sus consecuencias en el caso de los niños lebensborn. La eugenesia nazi constituyó uno de los proyectos más oscuros del régimen totalitario, desde esto, el caso lebensborn nos permite obtener una mayor perspectiva de estos hechos. Es por eso que, se intentará precisar gestación, nacimiento y posterior destino en las democracias de la posguerra, tomando como elementos biopolíticos intervinientes: las nociones de nuda vida y estado de excepción de Giorgio Agamben. Posteriormente, se intenta abordar la figura del Homo sacer en relación con lo acontecido en los campos de concentración de Auschwitz y la noción del poder soberano.

Palabras claves: Biopolítica - Estado de excepción - Eugenesia nazi - Lebensborn Homo sacer.

\section{Abstract}

The following article pretends to analyze the Nazi eugenics Project from the Biopolitics paradigm, and determine its consequences in the case of the Lebensborn children. The Nazi eugenics was one of the most dark projects of the totalitarian regime, from this, the Lebensborn case allows us to obtain a greater perspective of these facts. That is why, we tried to precise gestation, birth and the next fate in the postwar democracies, taking as biopolitics elements interveners: nuda vida and the state of exception's notions by Giorgio Agamben. Subsequently, we try to address the 
Homo sacer figure related to what happened in the Auschwitz concentration camp and the notion of sovereign power.

Key words: Biopolitics - State of exception - Nazi eugenics - Lebensborn - Homo sacer.

\section{Introducción}

El presente trabajo pretende ofrecer elementos necesarios para comprender el proyecto de eugenesia nazi desde el paradigma de la biopolítica. Para tal fin desarrollaremos un estudio del caso de los niños lebensborn su gestación, nacimiento y posterior destino en las democracias de la posguerra. Esta temática se ubica dentro del paradigma de la biopolítica bajo el sistema conceptual de Michel Foucault, las nociones de la obra Homo Sacer de Giorgio Agamben en relación a entender cómo la gestión política sobre la vida, que se manifiesta también a través de la manipulación del derecho, ha transformado la vida misma del hombre. En el proyecto de eugenesia nazi se determinan elementos como la nuda vida y el estado de excepción, esta perspectiva permite estudiar el caso de los niños lebensborn que, como resultado del proceso de selección racial pasaron su gestación, nacimiento y primeros años de vida en instituciones comandadas por el líder de la SS Heinrich Himmler. Posteriormente, interrumpido el proyecto, estos niños serán llevados a los países en que, se determinaba que provenían según la lengua que hablaban.

La hipótesis que funciona como guía de esta investigación consiste en sostener que, en tanto podamos especificar las dimensiones biopolíticas del proyecto de eugenesia nazi en relación a la noción de estado de excepción propuesta por Agamben, será posible considerar los elementos necesarios para la determinación del accionar democrático de los países de la posguerra sobre los niños lebensborn. Los objetivos que se disponen en el trabajo son: por un lado, en los objetivos generales se pretende analizar la noción de estado de excepción postulada por G. Agamben en relación al nazismo y las dimensiones biopolíticas presentes, reconstruir la estructura jurídico-política tanto del proyecto de eugenesia nazi como también los posteriores juicios de Núremberg. Por otro lado, se disponen objetivos particulares donde se aspira a: examinar la función del Soberano en relación al accionar democrático de los 
países restaurados en la posguerra, determinar la noción de nuda vida en el estado de excepción nazi, distinguir los objetivos del proyecto de eugenesia y también, especificar la figura del homo sacer.

En función de este panorama conceptual, es interesante examinar cómo se da el proyecto de eugenesia nazi y el caso de los niños lebensborn, recientemente documentado por los archivos históricos del holocausto, debido a los testimonios de estos niños -hoy adultos- que, como resultado de este proyecto han indagado sobre su origen y dan cuenta de ser lebensborn, es decir haber nacido en un centro de maternidad del sistema de salud del Tercer Reich. Este trabajo se enmarca dentro del análisis del problema filosófico "la vida en la biopolítica" del Segundo Seminario de Filosofía, profundizar las nociones del paradigma biopolítico se anuda a mis lecturas previas sobre esto desde la obra de Michel Foucault, la importancia que posee el filósofo Giorgio Agamben, como autor actual del campo biopolítico, hallará relevancia en el hecho mismo de su presencia como autor selecto en la bibliografía del seminario. La comprensión de los elementos intervinientes intentará echar luz sobre este hecho histórico y las disposiciones que los países -en su restauración democrática- fijaron, teniendo en cuenta su posicionamiento para determinar el destino de dichos niños.

Hablar sobre lo acontecido es en primer lugar el centro de relevancia sobre el tema, fundamentalmente porque las explicaciones no han logrado agotarlo y esto requiere una revisión sobre cuestiones filosóficas y políticas que poseen el fin de incorporar elementos actuales y de esta manera vuelve a emerger la importancia de dar cuenta sobre acontecimientos que escapan a la razón misma. Es importante señalar que las explicaciones pseudocientíficas y otras no han colaborado más que en echar tierra sobre el fenómeno más nefasto del cual se tenga registro. Esto adquiere relevancia en el campo filosófico por diferentes hechos: el abandono de Hanna Arendt a su nación aterrorizada por ver una Alemania de pensadores y poetas que se arrojaría a la ideología nazi, el trágico final del filósofo Walter Benjamin después de su exilio; y por último el hecho de que Theodor Adorno finalizará sus días rodeado de antiguos profesores nazis rehabilitados, entre otros. 
La estructura organizativa establecerá dos partes en la primera se abordará la noción de estado de excepción de Agamben y porque se considera al Tercer Reich uno de ellos, con esta profundización se dispone analizar dentro de este régimen dictatorial dos de sus consecuencias: el proyecto de eugenesia, su implicancia y lineamientos, además de los campos de exterminio. Posteriormente se analizará los resultados del caso de los niños lebensborn. En una segunda parte del trabajo se pretende abordar los hechos que acontecieron en Núremberg: las leyes promulgadas por el Tercer Reich y los juicios; continuando con la restauración de las democracias de la posguerra para finalmente poder retomar la figura del homo sacer y su importancia dentro del paradigma biopolítico.

\section{El nazismo como estado de excepción}

Durante las últimas décadas se ha constatado el uso de ciertas prácticas por parte de muchos gobiernos reservados a cierto sector de la población, un número menor de ciudadanos con tintes de constituirse como casos aislados pero algunos hechos demuestran que estas medidas -con un gran margen de aplicabilidad- se extienden a una totalidad poblacional. Un estado de excepción es un fenómeno jurídico que posee un rasgo esencial: "la provisoria abolición de la distinción entre poder legislativo, ejecutivo y judicial" (Agamben, 2001, p. 33). Esta separación entre los poderes del gobierno, en donde la titularidad de cada función es otorgada a un órgano distinto y separado de origen de los otros con el fin de limitar el poder, se ve anulada. Este fenómeno se conforma de manera provisional y extraordinaria tratándose también de un proceso que excluye: el estado de excepción logra excluir a los ciudadanos -o a cierto sector de la ciudadanía- y por tanto les hace perder su capacidad de ser personas es decir los aloja por detrás del derecho quedando a su disposición como vida desnuda. En referencia a esto Agamben señala "esta dislocación de una medida provisoria y excepcional que se vuelve técnica de gobierno amenaza con transformar radicalmente la estructura y el sentido de la distinción tradicional de las formas de constitución" (Agamben, 2001, p. 27). 
Tomando estas precisiones acerca del estado de excepción, el hecho que subraya con mayor dimensión dicha noción aconteció en la Alemania del Tercer Reich durante los doce años en que el partido Nacional Socialista Obrero Alemán gobernó en su forma dictatorial. Este período abarcó desde 1933 a 1945 y se considera el estado de excepción más desarrollado en la historia, las primeras medidas de este régimen consistieron en dejar en suspenso las garantías constitucionales que el Estado Alemán poseía, aprobando así medidas disciplinares extraordinarias -que una vez regidasencontraron amparo en la Constitución de Weimar, cual serviría de techo para estas leyes. En el estado de excepción nazi puede verse como se da una zona de indeterminación, donde se incluye lo que en biopolítica se denomina nuda vida: se trata de la existencia de la vida humana como mero cuerpo que se encuentra escindido de las forma de vida de la ciudadanía, quedando así totalmente desprotegida y a disposición de la decisión del oscuro soberano nazi. Esta cuestión es fundamental en el sentido biopolítico ya que devela y permite entender la estructura originaria de la soberanía, es por eso que Agamben va a realizar un análisis sobre esto para poder determinar que lo acontecido en este régimen permite entender que dentro de la estructura originaria de la soberanía existe una contradicción: este modo de vida desnuda se incluye en la categoría de la ciudadanía. Tengamos presente que aquellos que se encontraban bajo el nazismo, más específicamente en los campos de concentración eran "desprovistos de todo estatuto político y reducidos integralmente a una vida desnuda" (Agamben, 1998, p. 6).

El filosofo biopolítico presentará una particular atención por los campos de concentración, cuestión que más tarde será abordada en el desarrollo de este trabajo, y en su tesis principal, sostendrá que lo acontecido en dichos campos terminará por convertirse en nomos de lo moderno. Además de esto señalará que el estado de excepción será una técnica jurídico política a disposición del Soberano donde "el estado de excepción se presenta más bien desde esta perspectiva como un umbral de indeterminación entre democracia y absolutismo" (Agamben, 2001, p. 26). De esta manera el soberano será aquel que similar a lo considerado por Hobbes -en el estado natural- debía de tener el poder absoluto para poder gobernar y solo lo consigue a 
través del pacto, que realizado por los futuros súbditos exclusivamente entre ellos, permiten que el que decida en el estado de excepción, como también sostuvo Schmitt fuera el soberano. De este modo, para lograr la conservación del cuerpo jurídico con el cual el Estado registra la implementación del poder legal del soberano deberá negarlo en sí; se trata de aquellas medidas excepcionales que se tomaron como resultado de crisis, y que eran comprendidas desde el terreno político puesto que eran medidas jurídicas que se entendían en el plano político.

De esto se extrae que la estructura originaria de la soberanía opera cuando la ley incluye su posibilidad de cancelarse, es decir el soberano decide cuando la ley deja de tener valor en sí, ella misma habilita a que sea suspendida, esto es lo que va dar cuenta Agamben quien pone al descubierto la paradoja de la decisión jurídica, en donde el soberano se encuentra dentro y fuera de la zona de indeterminación. Así es como, dentro de esta zona la aplicación de la norma exige un medio homogéneo; es en ella donde se incluye la nuda vida, por medio de su exclusión inclusiva. El soberano será quien determina que se suspende la ley, el Estado será poseedor del monopolio de esta decisión y terminara constituyéndose la paradoja ya que, esta suspensión de la ley se da a través del mismo instrumento; otra ley, la cual retira el ropaje legal sobre una situación determinada que terminará por convertirse en norma más que en excepción. Agamben señala:

"el estado de excepción, sobre el que el soberano decide en cada ocasión, es precisamente aquel en que la nuda vida, que, en la situación normal aparece engarzada en las múltiples formas de vida social, vuelva a plantearse en calidad de fundamento último del poder político." (Agamben, 2001, p.15)

De esta manera se entiende la vigencia actual de lo acontecido en el régimen nazi, y como es que lo sucedido en las cámaras de gas de Auswitchz terminará por convertirse en modelo del estado de excepción, que fuera de las apariencias deviene cada vez más como norma dentro de la política actual. Retomar esto significó exponer el contexto en el que los niños lebensborn fueron gestados y criados, dando cuenta de los elementos biopoliticos intervienentes, ahora se abordan dos de las consecuencias 
sobre lo acontecido: los lineamientos del proyecto de eugenesia y la creación de los campos de concentración que se reconocen en esta trama.

\section{El proyecto de eugenesia}

Este proyecto significó una de las consecuencias más importantes que el estado de excepción nazi logro poner en funcionamiento, habiendo desarrollado los elementos principales de la biopolítica nos disponemos a entender el tipo de vida que el nazismo tenía bajo sus fines. La noción de raza fue principal en el sistema ideológico nazi y también su fundamento primordial, es por eso que, entre los objetivos más oscuros del régimen, se construyó un proyecto que poseía fines eugenésicos, el cual revelaría la piedra angular del Tercer Reich que consistía en sostener su superioridad alegando pertenencia directa con los "arios". De ello se extrae que "el estado nacional ha de colocar la raza en el punto central de la vida de la comunidad y velar por su pureza" (Guerra-García, Ávila-Morales y Acuña-Barrantes, 2015, p. 67). Por una parte es posible que esta idea encuentre raíces en la misma mitología nórdica de donde se obtiene que existieron cuatro grupos germánicos de los cuales uno de ellos era poseedor en mayor medida de los rasgos "arios" más distintivos es decir, eran altos rubios y sus ojos azules, luego de que este grupo comenzará a reproducirse con lo demás grupos los rasgos fueron perdiéndose y dejaron de ser distintivos.

Desde otro punto fue solo una explicación que se construyó con el esfuerzo por sostener descendencia de la estirpe originaria de los indoeuropeos, un invento que funcionaría como propaganda y que proponía que los originarios europeos surgieron de los antiguos pueblos germánicos, el denominado Volksdeutsch. Foucault señala esta cuestión estableciendo que "el nazismo utilizará toda una mitología popular, y casi medieval, para hacer funcionar el racismo de Estado dentro de un paisaje ideológicomítico" (Foucault, 2008, p. 73). Mayormente es este segundo argumento el que se sostendría sobre concepciones pseudocientíficas puesto que no hay registros posibles de lo que se presenta. El hecho de la raza superior sugiere la posibilidad de tres elementos fundamentales, en primer lugar la idea de que el hombre puede siempre mejorar desde un notable estilo darwinista, en segundo lugar el hecho de que hay 
seres mejores que otros y que son factibles de ser comparados y en tercer lugar la búsqueda de la perfección biológica y psicológica que se relación con ideales del progreso.

La propaganda nazi se centraría en rasgos externos y físicos que ni el mismo Hitler poseía, pero se da cuenta que lo más importante no eran las características externas como se piensa, sino el hecho de estar exento genéticamente de rastros de pertenecía judía, desde esto se construyó la idea de "ario"; es este posible parámetro el cual permitirá a los nazis diferenciar alemanes de judíos. Desde los instrumentos legales se puede evidenciar el registro de una ley que clasificaría al "no ario" como todo aquel que poseyera un abuelo no ario, la definición se sustrae de clasificaciones publicadas por la "Ley de ciudadanía del Tercer Reich" en donde se señala la definición de judío como "todo aquel que desciende, al menos, tres abuelos total y racialmente judíos" (Guerra-García et al., 2015, p. 65).

Foucault señala que Hitler se veía a sí mismo como parte de un Estado racista "encargado de proteger biológicamente la raza" (Foucault, 1976, p. 73), este será considerado el primer estadista que llegaría a reconocer la biología hereditaria y la higiene racial para conectarla con los principios básicos de una política, es decir la ciencia se desarrolla a través de una ideología política y el Estado es el gran benefactor de ello, esto sería "una prueba inefable de la relación entre ciencia y política para el Tercer Reich" (Guerra-García, Ávila-Morales y Acuña-Barrantes, 2015). La Oficina de la Raza y el Reasentamiento que poseía como fines la verificación de los estándares raciales y genéticos habría creado la figura del examinador racial como lo señaló Foucault en cuanto al desarrollo de la medicina social, la policía médica, esta figura que demostraba la intervención del Estado en la salud de la población puesto que consideraba al cuerpo "como una realidad biopolítica, la medicina es una estrategia biopolítica" (Foucault, 1999, p. 366).

La eugenesia refiere a la aplicación de leyes desarrolladas por la biología, con el fin de perfeccionar la especie humana, es por eso que la puesta en marcha de políticas eugenésicas buscaba desarrollar el germen de la "raza superior", si bien esta posee 
bases científicas no es considerada una ciencia, sino más bien un intento por mejorar la genética humana. La acción sería entonces que "el hombre dada su raza escoja entre sus congéneres quienes son dignos de aparearse y quienes no" (Guerra-García et al, 2015, p. 65). La política eugenésica nazi tendría dos objetivos fundamentales, por un lado eliminar y por otro construir la "celular germinal nazi". Este último objetivo conllevaba la formación del compatriota quien no solo debía poseer sangre alemana sino que además debía tener la capacidad y el deseo de pertenencia al pueblo alemán. Este será el lineamento fundamental para el proyecto lebensborn quien materializaría los ideales eugenésico nazis. El objetivo de eliminar poseía dos enfoques principales aunque ambos tendrían la premisa de combatir, en el primero se trataba de esterilizar tanto a niños como aquellos a los que se consideraban inferiores, los débiles los ancianos los enfermos y los que poseían un coeficiente intelectual bajo. El segundo consistía en el exterminio que surgía como solución de la llamada "cuestión judía" enfoque que se profundiza en el siguiente apartado.

\section{Los campos de exterminio}

Como segunda consecuencia, el estado de excepción nazi habría llevado bajo sus fines a los individuos a condiciones extremas, creando una de las más grandes maquinarias de exterminio que aconteció en la historia: los campos. Para poder hablar sobre lo acontecido en los campos de exterminio, es menester referir primero a la visión historiográfica que adquiere relevancia, tratando de poner en énfasis en la racionalidad instrumental y burocrática del exterminio ocurrido en los campos de concentración de Auschwitz. Es decir, además de tratarse del fenómeno más perverso ocurrido se pone de relieve el esfuerzo logístico de aquellos que han sido ideólogos como aquellos que en sus manos han llevado tareas, tratándose de personas comunes y corrientes, ciudadanos alemanes que no habrían sido purgados y que habrían sido puestos en las filas de los asesinos. De esta manera se pierde completamente la distinción entre asesinos nazis y ciudadanos civiles, esto fue potencial en el asesinato masivo e industrializado que se desencadenaría en los campos de exterminio siguiendo lo señalado por Tendlarz "en Auschwitz no se moría, se producían cadáveres" (Tendlarz, 2013, p. 86). Así el campo de extermino se definirá como "el más absoluto 
espacio biopolítico que jamás se haya realizado, en el cual el poder no tiene frente a sí sino la más pura vida biológica, sin mediación alguna" (Agamben, 2006, p. 217).

Dentro de estos fines el fenómeno mayor logrado se denominó Sonderkommando que se trataba de prisioneros obligados a conducir a otros prisioneros, es decir se habría desarrollado una lógica que disponía a los mismos ciudadanos corrientes realizar actividades en fin de la sanguinaria industrialización de cadáveres. Estos podían acompañar a otros prisioneros, examinar en sus cuerpos si poseían objetos de valor para posteriormente llevarlos a las cámaras de gas y así también a las tumbas. De esta manera, colaboraban en su accionar puesto que se encontraban bajo el oscuro soberano nazi y estaban dispuestos -pasivos ante la muerte del otro- en una pausada muerte simbólica que no terminaría de cesar, y a la cual solo le queda, la espera del fin del cuerpo biológico. Se entiende que en "el campo, al haber sido despojados sus moradores de cualquier condición política y reducidos íntegramente a nuda vida, es también el más absoluto espacio biopolítico que se haya realizado nunca, en el que el poder no tiene frente a él más que la pura vida sin mediación alguna" (Agamben, 2006, 217).

La tesis planteada por Sneth y Cosaka expone el hecho de que "el nazismo no es el paroxismo del discurso racista sino, que consiste en el exterminio del discurso" (Tendlarz, 2013, 84). Este exterminio del discurso permitía hacer que los asesinos se desentiendan del crimen y eso eliminaba por completo la categoría del verdugo, debido al uso del anonimato por parte de los perpetradores de terribles actos. Estos eran participes de la "solución final", dando un "tratamiento especial" a los que se encontraban "reagrupados" y demás denominaciones neutras para un uso positivo de camuflaje. Este se trató de un "lenguaje administrativo y como recurso de propaganda y ocultamiento, lo que permitía llevar a cabo las tareas de la matanza sin llamarlas por su nombre" (Tendlarz, 2013, p. 84). Este análisis también será considerado desde la perspectiva biopolítica por Foucault, en su genealogía del racismo donde establece que "el nazismo no es otra cosa que el desarrollo paroxístico de los nuevos mecanismos de poder instaurados a partir del siglo XVIII" (Foucault, 1976, p. 209). Hasta aquí hemos 
abordado las consecuencias fundamentales del nazismo y es importante destacar que tanto los procesos eugenésicos sistemáticos, como los campos de concentración significaron la acción del nazismo sobre la población, cuestión que se retomará mas adelante. Es por eso que ahora, intentaremos profundizar la eugenesia nazi en su materialidad refiriendo a la gestación de los niños lebensborn.

\section{El caso de los niños lebensborn}

Los niños lebensborn fueron gestados bajo los fines del proyecto de eugenesia que el Nazismo llevo a cabo durante los años 1935 hasta 1945, desde una política dictatorial y un esfuerzo logístico descomunal que habría organizado las instituciones lebensborn, asociación dependiente de las SS que fomentaba la producción de "arios" en el territorio Alemán y las demás naciones que el Tercer Reich habría tomado. El proyecto pretendía que los niños fueran portadores de ciertos rasgos y que estos se mantuvieran para identificarse y expresar en su mayor potencial la llamada "pureza aria" es por eso que, la mayoría de estos provenían de padres escandinavos seleccionados minuciosamente. Como lo expresa el informe de Gómez donde señala "se trató de un experimento para reproducir la raza aria" (Gómez, 2006, p. 1). Himmler fue el gran impulsor de la asociación lebensborn, este era un hombre importante para el Tercer Reich puesto que poseía el mayor rango como oficial nazi de las SS y además era uno de los principales líderes del partido NSDAP, consideraba que los soldados de las tropas SS eran la vanguardia de la raza superior es por eso que los veía como modelos a seguir en la conformación del proyecto. Así es como muchos de los procedimientos que se llevaron a cabo en el proyecto tenían un vínculo directo con las tropas SS. La existencia de estos niños, o el hecho de que estos niños hayan sido posibles a través de un plan sistemático demuestran la entrega de la nuda vida a disposición del poder soberano, puesto que para constituirse la figura del ciudadano existe esta entrega. Esto será señalado por Agamben quien expone "en la medida en que alguien es ciudadano, ya no es más mero viviente; pero al mismo tiempo, para ser ciudadano pone su vida natural, su nuda vida, a disposición del poder político" (Agamben, 2004, p. 7). 
En un análisis sobre otras denominaciones que estos niños recibieron, también son denominados hijos de la vergüenza, etimológicamente la palabra vergüenza proviene del latín verecundia y refiere a la turbación ocasionada por la conciencia de alguna falta cometida, o por alguna acción deshonrosa la cual sería la razón de la denominación que recibían al tratarse de niños nacidos extraconyugalmente. De esto se extrae que la acción devendría, desde el hecho en que los soldados para mantener su jerarquía debían engendrar la mayor cantidad de hijos posibles, incluyendo la posibilidad de que estos estuvieran fuera de su matrimonio es decir, con otras mujeres fuera de su relación conyugal como lo habría dispuesto Himmler. Jóvenes que luego debían tener a sus hijos en instituciones que formaban parte del proyecto lebensborn. Si bien esta era la fuente directa de los niños que estuvieron en el proyecto lebensborn muchos de ellos también fueron secuestrados de países que durante 1939 fueron tomados por el régimen nazi los cuales poseían rasgos "arios".

Es un hecho que los niños lebensborn nacen en centros paritorios y es por eso que la denominación que reciben hace referencia a su relación directa con el proyecto lebensborn, que traducido del alemán se obtiene "fuente de vida". Los datos que se adquieren de la infancia de estos niños demuestran que principalmente consistiría en cuidados realizados por profesionales médicos y enfermeras que tomaban registros, y mediciones de cada uno de ellos con el fin de evaluar que cumplieran los parámetros establecidos, y en caso de tratarse de algún "desperfecto" serían excluidos del grupo. De esta manera, se señala que "pasaban estos por la demostración de una ascendencia por completo aria u por la superación de un examen médico que certificara buena salud y rasgos que cumplieran los criterios estéticos del hitlerismo" (Gómez, 2006, p. 1) Aquellos cuidados higiénicos y de salud en relación a su primera infancia eran dados por enfermeras con quienes no guardaran ningún tipo de vínculo más que aquellas actividades de higiene y alimentación.

Si bien durante el período nazi hubo diferentes crisis económicas que se hicieron sentir en la población y muchas veces en las tropas, estos niños tenían un lugar de privilegio en la economía nazi y por tal motivo no sufrieron ningún tipo de 
carencias. Desde la perspectiva biopolítica, esto deja en claro el tipo de vida que los nazis querían preservar, vidas que a través de procesos eugenésicos fueran alteradas a sus fines, y sujetos que respondieran a su discurso. Como lo señala Foucault "el control de los riesgos específicos de los procesos biológicos era de hecho uno de los objetivos esenciales del régimen" (Foucault, 2008, p. 209).

Como hecho significativo, se extrae que fueron bautizados en sus primeros años con rituales similares a los del cristianismo que tenía como objetivo el comienzo de una adoctrinamiento siniestro, proceso que sustituiría el bautismo cristiano, este ritual era realizado junto con los soldados de la SS ya que es a través del anillo distintivo del régimen nazi que era utilizado para realizar el ritual. Una vez finalizada su proceso de crianza los niños eran dados a familias de las SS, denominadas familias de acogida, borrando así los datos de sus progenitores biológicos, este proceso sería denominado repatriación o también germanización y era el final del proyecto, se producía aproximadamente cuando estos niños cumplían los diez años.

En relación a lo institucional, los mayores centros lebensborn se instalaron en Steinhoring -un pueblo bávaro cercano a Múnich- donde todavía se encuentran los registros de los nacidos lebensborn, el principal centro paritorio del proyecto. También fue estratégico para el régimen instalar un centro Lebensborn en la ciudad de Oslo -al sur de Noruega- debido a que era el lugar donde descansaban los soldados alemanes y el propósito consistían en que estos conocieran a mujeres noruegas y procrearan; de esto se obtiene que "Lebensborn aparece como el lugar de encuentro entre jovencitas y hombres de la SS, una suerte de picadero subvencionado donde mujeres rubias e ingenuas eran violadas por nazis de uniforme" (Gómez, 2006, p. 2). La procedencia noruega era buscada por el proyecto debido a que se creía que el pueblo noruego cumplía mayormente los rasgos del Volkdeutsch, esto se establecía dentro de los objetivos del ideólogo nazi Himmler quien establecía esta identificación perfecta de los noruegos con los rasgos arios. El resultado del proyecto de eugenesia nazi obtuvo cifras significativas pero este centro de Oslo habrían gestado 10 mil niños, obteniendo el mayor índice de natalidad del proyecto en relación al total seria de 22 mil niños 
lebensborn. De esto se tiene que el Estado no solo fue cómplice de un horror moral inadmisible sino que además proyectó entre sus fines la procreación de subjetividades alteradas que provendrían de esto para reafirmar su argumento racial. Hasta aquí hemos podido evidenciar el accionar del estado de excepción nazi sobre los niños lebensborn, pero un análisis sobre ello indica hablar sobre el momento actual en el que estos se encuentran, cuestión del siguiente apartado.

\section{Los lebensborn hoy}

El nacionalsocialismo trajo extremas consecuencias al desarrollo de la humanidad, consecuencias que pueden ser vistas en la actualidad que tienen que ver con mucho más que datos meramente históricos, puesto que el proyecto lebensborn fue una materialización de los fines eugenésicos pero también fue creador de vida. De niños que nacieron, crecieron y que hoy ciudadanos de distintos países se preguntan sobre su relación con un pasado histórico que los trasciende. En la actualidad los niños lebensborn -hoy adultos- han indagado sobre su procedencia, enfrentándose con sus orígenes, muchos de ellos han encontrado en los registros de su infancia elementos que poseen alguna vinculación con el Tercer Reich, tratándose de fotografías con soldados de las SS o comentarios de algunos familiares sobre ello, y dieron cuenta de un pasado secreto que si bien se les habría negado por el llamado secreto de estado, los registros históricos aún persisten.

Aquellos edificios que habrían pertenecido a el proyecto hoy hablan y el movimiento humanitario Cruz Roja Internacional puede dar acceso a los registros que documentaron la pertenencia de muchos al proyecto lebensborn. Otros no han podido preguntarse, mientras que algunos no se han podido quedar sin respuestas acerca de sus orígenes, sobre quiénes fueron sus padres, cual fue la razón por la cual decidieron dejarlos en estas instituciones; donde se encuentran en la actualidad, si perteneciendo a este proyecto fueron criminales implicados en el nazismo o no, teniendo en cuenta que han pasado ya más de 60 años. Los que han encontrado respuestas se han sentido determinados por hacer algo, no han podido liberarse de un pasado como lo expone el 
informe de Goméz donde "el sentimiento de culpa es una constante en las narraciones de los que han decidido contar su historia" (Gómez, 2006, p. 2).

Un sentimiento de culpa que ha condicionado en gran medida su presente, y es así como han decidido pertenecer a la fundación Lebensspuren (huellas de vida), que se formó en el año 2005, y se permitieron la vinculación con muchos otros que habrían sido parte de este proyecto. Esto significó una salida a los interrogantes que estas personas se plantean en su vida actual, un escape al sentimiento de culpa que encuentra una manera de cuestionar lo sucedido y revisar algunas "verdades" sepultadas por medidas tomadas por los gobiernos. Encontrándose así con lo paradójico que puede resultar estar en buenas condiciones en momentos donde se vivió el crimen más grande de la historia de la humanidad, desde lo terrible devienen sus infancias rasgadas. De esta manera lograrían exponer su experiencia y además recibir apoyo mutuo, su directora ante los fines de esta fundación expone que se trata de "asumir de este modo un compromiso ético para que, en palabras de su directora nunca se repita lo que sucedió antes" (Gómez, 2006, p. 2).

\section{Los hechos acontecidos en Núremberg}

\section{Las leyes de Núremberg}

Reconstruir la estructura jurídico-política de lo acontecido implica retrotraernos a dos situaciones fundamentales: algunas de las medidas más extraordinarias que se dictaminaron en la ciudad de Núremberg, y además los juicios que acontecieron en el fin de la guerra. Comenzando con la primera situación conocemos que Núremberg fue la ciudad que mayor adhesión poseía al régimen nazi por tanto la ciudad favorita del nazismo. Núremberg constituyó el sistema judicial del Estado Alemán que promulgó leyes, decretos y órdenes que llevarían a cabo los planes del Tercer Reich, entre ellos el programa de eugenesia y el exterminio en los campos que desarrollamos anteriormente. Con el fin de determinar la estructura jurídico-política posibilitadora de estos sucesos, se pone en relieve las leyes de Núremberg cuales consistirían en la estructura que amparó las medidas tomadas por Hitler, constituyendo la rama judicial del Estado Alemán. 
Las medidas del régimen nazi encontraron amparo en la Constitución de Weimar, la cual serviría de techo para las leyes que se aplicaron. Específicamente dicha constitución establecía que bajo ciertas circunstancias -según el artículo 48- se podía adoptar diversas medidas de emergencia, las cuales habrían sido funcionales a las políticas de Partido Nazi. Esto fue señalado por Agamben quien explica que "el decreto no fue nunca revocado, de modo que todo el Tercer Reich puede ser considerado, desde el punto de vista jurídico, como un estado de excepción que duró doce años" (Agamben, 2004, p. 25).

Durante el año 1935 se comenzó a aplicar leyes que anularían a los judíos la posibilidad de ser compatriotas, dando como primer paso fundamental sin importar la nacionalidad que poseían. Este hecho posee relevancia puesto que Agamben señala que después de las leyes de Nuremberg "los judíos sólo podían ser enviados a los campos de exterminio una vez que hubieran sido completamente privados de la nacionalidad" (Agamben, 2006, p.168). Lo cual permitió establecer la figura del ciudadano alemán que debía de poseer no solamente linaje germánico sino a demás capacidad y deseo de pertenencia al pueblo alemán, justamente la figura del compatriota era lo que permitía instalar la sumisión a Hitler "el alma racial, la sangre y su misterioso atractivo es el poder inmanente y superior encarnado en el pueblo la sumisión al Führer, tratándose de un poder incondicional y absoluto" (Poliakov, 2011, p. 20). Las decisiones del régimen se tomaban y se documentaban en el Reichstag, el conocido parlamento Alemán, aquellas primeras medidas que fueron anunciadas sucedieron en Septiembre de 1935 donde se sancionó la "Ley para la protección de la sangre y el honor alemán" que dispuso ciertas medidas siendo este un momento fundamental para la exclusión y el éxito del nacionalsocialismo. La ley poseía el objetivo de garantizar el porvenir de la nación alemana evocando que la pureza de su sangre es la perpetuación del pueblo alemán, de esta manera la ley dispone prohibir el matrimonio entre judíos y alemanes, como así las relaciones extraconyugales entre los mismos. Los judíos deberán cesar de tener en su personal doméstico mujeres alemanas y también dispone que queda a resguardo del Estado el ejercicio de hacer visibles colores alemanes a exclusividad de los mismos alemanes, en caso de que se 
cometa una infracción con alguna de estas prohibiciones la misma sería penada con reclusión o encarcelamiento.

\section{Los juicios en Núremberg}

Para retrotraernos a esta situación fundamental es importante referir a una fecha puntual donde se halla el centro de relevancia de la estructura jurídica, el 20 de Noviembre de 1945 donde se desarrollaron los procesos jurisdiccionales iniciados por las naciones aliadas vencedoras de la Segunda Guerra Mundial. Durante un determinado período las autoridades que comandaron este proyecto fueron investigadas con el fin de determinar responsabilidades, pero ninguna de ellas fue juzgada por estos actos y todas las acciones desarrolladas en el proyecto lebensborn fueron consideradas como parte de un accionar, que intentaba ofrecer lugares de tránsito a esos niños que se encontraban desprotegidos en la guerra. De esta manera esta situación ha quedado impune puesto que dicho accionar no poseía intenciones hospitalarias ni mucho menos de protección, dejando absueltos a responsables de delitos que no habría podido ser demostrados. Este acontecimiento histórico permite mostrar lo señalado por Agamben en la política actual puesto que se ve como se "liga, y al mismo tiempo se abandona al viviente en manos del derecho" (Agamben, 2004, p. 24) Recordemos que con esto, la política deviene biopolítica porque el estado de excepción es la estructura originaria que funda la biopolítica moderna "incluye a la vida natural dentro de los cálculos del poder estatal” (Agamben, 2004, p. 7).

\section{Las democracias de la posguerra: el accionar de Francia y Noruega}

Reinstauradas las democracias -después de la caída del Tercer Reich- los países recuperaron sus organizaciones jurídico-políticas, una vez que las tropas americanas dan cuenta de las instituciones del proyecto lebensborn los niños fueron retirados de estos lugares y devueltos a los países a los cuales tenían correspondencia según la lengua que hablaran. Dos países tuvieron una particular decisión respecto de estos niños: por un lado Francia quien habría decidido borrar sus documentos para que no descubrieran que fueron parte del proyecto lebensborn y por otro lado, Noruega decidió instalarlos en instituciones mentales porque consideraban que habían tenido 
un desarrollo subnormal y por tanto no podían restituírseles como niños normales. Posteriormente, lo que se recupera de los testimonios actuales de los niños lebensborn quienes hablan sobre este acontecer, mencionan que se los habría considerado retrasados mentales diagnosticados por los médicos del Hospital Nacional de Oslo, en el caso de Noruega. Estas acciones permiten develar lo contradictorio en la estructura originaria de la soberanía puesto que la misma opera cuando la ley incluye la posibilidad de cancelarse. Agamben hará referencia a este hecho tratándose de una "ambigüedad constitutiva del orden jurídico por el cual éste parece estar siempre al mismo tiempo afuera y adentro de sí mismo, a la vez vida y norma, hecho y derecho." (Agamben, 2004, p. 14) Es decir, la ley se encuentra a disposición del Soberano, pero para accionar sobre la población y tomar medidas extraordinarias este hace uso del estado de excepción justamente a través de una ley. Es esto lo que constituye un hecho paradójico puesto que la ley habilita a que la misma ley sea suspendida para que el soberano pueda actuar sobre los individuos quitándoles el ropaje jurídico. Y de esta manera volviéndolos a la categoría de nuda vida.

Si pensamos en el accionar de los países de la posguerra vemos que el derecho a la identidad de los niños lebensborn fue negado, donde todavía se sigue sosteniendo el racismo, "es esencialmente a través de este como la biopolítica deviene una tanatopolitica o una política de la muerte" (Lemm, 2015, p. 236). Siguiendo esto los estados responsables, Francia y Noruega debieron de iniciar investigaciones sobre estos hechos para intentar resolver el origen de estos niños, pero contrario a esto las decisiones tomadas sepultaron estos hechos y pudieron hacerlo amparándose en dos cuestiones: así como el estado nazi pudo decretar medidas amparándose en la constitución de Weimar como lo analizó Agamben, el accionar de estos países para con los niños lebensborn fue posible gracias a la potestad que el Estado posee sobre los individuos y además en el hecho de que nada habría por investigar puesto que en los juicios de Núremberg los responsables de estos hechos habrían quedado impunes: la institución lebensborn fue vista como una asociación solidaria y de hospitalidad que resguardaba a los niños de la situación de guerra, considerándose hasta un modelo institucional a seguir. 
Cuando el reclamo por discriminación de los niños lebensborn al Estado Noruego fue efectivo, decidieron darle una remuneración pero evitaron hacerse cargo de lo que había sucedido. Se consideró durante mucho tiempo a estos niños con la denominación de pertenecer a una "quinta columna" termino bélico que hace referencia a un sector de la población que pertenece al enemigo y que permanece infiltrado en la población propia es decir, se consideraba a estos niños potenciales en la afectación que podrían producir puesto que estaban bajo el dominio del nazismo. En vez de victimas nuevamente. A diferencia del accionar del Estado Francés quien habría exterminado este miedo puesto que se habría borrado todo tipo de señal de pertenencia de estos niños a las instituciones lebensborn, de esta manera indagar sobre su pasado habría sido más difícil ya que se debía suplir la falta de registros y documentos. El daño es irreparable, es posible que todas las dimensiones de esto no hayan siquiera permitido a los padres buscar a esos niños que habrían dejado en manos de otros. El miedo, el desconocimiento y el dolor no hacen más que censurar un accionar que permitiese cerrar heridas que los estados mismos decidieron dar la espalda en su responsabilidad, como señala Foucault "la soberanía se forma siempre desde abajo, a través de la voluntad de los que tienen temor" (Foucault, 2008, p. 83) No se esperaría esto después de lo acontecido, todavía se sigue indagando y muchas decepciones acontecen en la vida de estos, pero jamás serian reconocidos como víctimas de guerras, más bien se trata de niños huérfanos a quienes una vez más se les ha negado su propia identidad.

Después de toda una vida viviendo con una supuesta identidad la asimilación hacia una identidad desconocida es trágica, la sensación de pertenencia el nacimiento en un paritorio nazi y la pregunta más difícil, nacido por amor o nacido por "amor" al nacionalsocialismo. Aceptar este nacimiento es asumirse como víctima con un gran nivel de afectación y no es fácil determinarse como tal sobre todo porque se conoce la presión social que esto acompaña, es decir el temor de la gente y la crueldad estatal que se conjugan para conformar daño y exclusión; ayer pero también hoy cuando se intenta conocer el origen de lo sucedido. Para cerrar este capítulo podemos ver como las nociones tienden a encontrarse, permitiendo encontrar una explicación más 
detallada sobre el accionar democrático en los países de la posguerra, que en sus gobiernos democráticos toman medidas extraordinarias para con los niños lebensborn. Develando así el poder soberano sobre la población y por tanto, la contradicción que subyace la estructura originaria de la soberanía, la cual permite al soberano tener la potestad de decidir, en el estado de excepción sobre los individuos puesto que todos ellos se convierten en nuda vida y es este quien puede disponer de sus vidas. Intencional fue situar, una de las nociones del paradigma biopolítico, en esta última parte del trabajo para subscribir en ella los elementos intervinientes.

\section{La figura del homo sacer en la obra de Agamben}

Los esfuerzos agambenianos por desarrollar la figura del homo sacer se plantean dentro de lo que el autor denomina la "máquina gubernamental" y su análisis establece dos ejes exploratorios fundamentales, por un lado, la soberanía y por otro la economía. Dicha figura establecería un giro en el campo de la biopolítica con la obra "Homo Sacer I" de gran influencia dentro de la filosofía política. Su obra compuesta por cuatro partes se inscribe dentro del sistema conceptual de Michel Foucault quien anuncia el devenir de la política en biopolítica y destaca la introducción de la vida en los mecanismos del poder del Estado. Agamben considerará a las prácticas biopolíticas como la captación de la vida humana por parte de la política es por eso qué recuperará una antigua figura del derecho romano arcaico: el homo sacer. Tratándose de una figura que se logra a través de un delito cometido por un sujeto que como consecuencia de esto queda expuesto totalmente a la muerte, es decir su vida se transforma en vida desnuda -vida desprovista de toda investidura jurídica- de manera que cualquier individuo podría darle muerte sin que esto se considere un acto homicida. En relación a esto Agamben señala que se trata de "la definición de una vida a la que se puede dar muerte sin cometer homicidio" (Agamben, 2006, p. 209) quedando así su vida en el desamparo, por fuera del derecho. Ejemplo de ello será el "musulmán" de Auschwitz, es decir aquel individuo que se encontraba en el campo de exterminio nazi y habiendo perdido su nacionalidad puesto que solo tendría una nacionalidad reciclada y debido a las condiciones inhumanas que lo acontecían deviene musulmán una tercer categoría entre vivos y muertos que "quedaban 
petrificados en sus necesidades básicas y deambulaban como muertos vivos" (Tendlarz, 2013, p. 86). Si bien el homo sacer era sagrado el mismo no podría ser sacrificado pero quedaba expuesto al poder del soberano y su muerte no tenía ningún valor. En relación a esto "el nazismo hace de la nuda vida del homo sacer, definida en términos biopolíticos y eugenésicos, el lugar de una incesante decisión sobre el valor y el disvalor, en que la política se transmuta permanentemente en tanatopolítica" (Agamben, 2006, p. 194).

En un análisis sobre el termino Sacer se extrae que proviene de la lengua latina y significa "sagrado restringido o dedicado a una divinidad", eran los romanos quienes le daban un doble sentido ya que no solo se trataba de aquello que era consagrado a lo divino sino que además era lo maldito, lo execrable aquello que podía ser víctima. Teniendo en cuenta esto, la figura del homo sacer correspondía a una figura oscura del sistema jurídico romano estableciendo que sagrada es la vida que está dentro del derecho y que para salvaguardar esta vida el poder soberano necesita de vidas prescindibles estableciendo así una economía de la supervivencia. Agamben ejemplificará esta figura haciendo referencia a los sujetos exterminados en los campos de concentración nazis, quienes en la industrialización de la muerte, situaban al individuo -como mera vida física- al margen entre la ciudadanía y la vida social. De esta manera se subraya como los judíos fueron inscriptos paradójicamente en una organización institucionalizada destinada al exterminio.

De este modo, los conceptos sobre biopolítica terminan por conectarse en esta última noción desarrollada puesto que el homo sacer es la nuda vida, un cuerpo que se encuentra escindido de la forma de vida del ciudadano y por tanto queda totalmente desprotegido. Agamben dirá que es justamente el soberano aquel que decide sobre el estado de excepción y también por el homo sacer puesto que, la vida de este, sagrada, pero a la vez insacrificable va a fundar un espacio político que otorga al soberano el poder de dar muerte y de esta manera también lo sostiene. Finalmente, el hombre sagrado dará contenido al soberano y por tanto este aloja a la nuda vida como elemento político original, como umbral de articulación entre el bios y la zoé. Es por 
eso que Agamben afirmará que el hombre moderno no difiere del homo sacer, en la medida en que su suerte depende de la voluntad del poder soberano. En palabras del autor "la producción de un cuerpo biopolítico es la aportación original del poder soberano" (Agamben, 2006, p. 16).

\section{Conclusión}

La hipótesis principal de este trabajo pretendía sostener que en tanto podamos especificar las dimensiones biopolíticas del proyecto de eugenesia nazi en relación a la noción de estado de excepción será posible considerar los elementos necesarios para la determinación del accionar democrático de los países de la posguerra sobre los niños lebensborn posee un resultado afirmativo. Puesto que se logró realizar un abordaje del nazismo como un estado de excepción que sirvió para entender el contexto en el que se produjo la gestación de los niños lebensborn, y de que manera las instituciones lebensborn habrían materializaron el delirio eugenésico nazi. También se expuso como la creación de los campos de concentración y el proyecto de eugenesia demuestra de qué manera se produce una acción por parte del soberano sobre la población, rescatando la noción biopolítica de nuda vida. Y por último, el accionar democrático de los países de la posguerra develó el poder soberano sobre la población, la cual permite al soberano tener la potestad de decidir dentro del estado de excepción, sobre los individuos puesto que todos ellos, se convierten en nuda vida y es este quien puede disponer de sus vidas.

El accionar democrático de la posguerra -de los estados Franceses y Noruegopuede ser entendido desde el paradigma biopolítico puesto que para el nazismo los niños lebensborn se habrían constituido como aquel tipo de vida que había que preservar, el cual el oscuro soberano nazi debía mantener y sólo se puede entender el exterminio en los campos como aquel tipo de vida que había que dejar morir, vidas desnudas que se alojan en un estado no punible. También, dicho accionar devela lo contradictorio que existe en la estructura originaria de la soberanía, puesto que en vez de tomar medidas para investigar el origen de los niños, estos fueron prescindidos, negados y victimizados nuevamente. Los Estados se habrían amparado en dos 
elementos: el primero es que en los juicios de Núremberg los responsables no habían sido declarados culpables y el segundo es el uso de la función de secreto de estado.

La referencia a la tesis de Sneth y Cosaka, acerca del exterminio del discurso por parte de los nazis, nos permitió indagar sobre el nivel de afección que posee la acción del poder Soberano en la población, puesto que señala la manipulación del lenguaje para obtener sujetos determinados y marcados. En relación a esto, Agamben nos expone que habrá política solo en tanto exista lenguaje, es decir existan seres hablantes, que se constituyan en un lenguaje como sujetos correlativos cual poseen una perdida, es decir una posibilidad de no determinación, dicha perdida será afectada por la ideología nazi. La manipulación del lenguaje para finés ideológicos afectan el pensamiento, Agamben subraya que mientras mantengamos el pensamiento no puede haber nuda vida.

Por último, podemos extraer desde una perspectiva actual que lo que acontece en estos últimos años -en la actualidad- donde se trata convencernos de que debemos aceptar como dimensiones humanas y normales de nuestra existencia prácticas de control que habían sido consideradas excepcionales. La historia puede mostrarnos que estas prácticas reservadas al comienzo a los extranjeros enseguida se aplican al conjunto de los ciudadanos, convirtiendo así el estado de excepción en regla. Solo si podemos entender la soberanía y el biopoder confluyen en la producción de los estados de excepción -en tanto dispositivos que capturan y producen en un mismo movimiento- nudas vidas entenderemos la forma de producción e industrialización de la muerte como así la gestación de niños alterados a través de procesos eugenésicos del Tercer Reich. Quedando esto demostrado, actualmente las ciudades se expresan con arquitecturas magnas y poderosas ostentando cual poder carecen puesto que la ciudad no será el nomos de lo moderno -siguiendo los lineamientos de Agamben- "el campo de concentración y no la ciudad es hoy el paradigma biopolítico de Occidente" (Agamben, 2006, 230). 


\section{Bibliografía}

Agamben, G. (1998). ¿Qué es un campo? Buenos Aires, Argentina: Editorial Artefacto.

Agamben, G. (2001). Medios sin fin. Valencia, España: Editorial Pre-textos.

Agamben, G. (2004). Homo sacer II: I. Estado de excepción. Buenos Aires, Argentina: Editorial Adriana Hidalgo editora.

Agamben, G. (2006). Homo sacer: el poder soberano y la nuda vida. Valencia, España: Editorial Pre-textos.

Foucault, M. (1998). Historia de la sexualidad I: la voluntad de saber. Madrid, España: Editorial Siglo XXI.

Foucault, M. (1999). Obras esenciales II. Estrategias de poder. Barcelona, España: Editorial Paidós.

Foucault, M. (2008). Curso en el College de France (1975-1976). Defender la sociedad. Buenos Aires, Argentina: Editorial FCE.

Guerra-García, Y. M., Ávila-Morales, J.C. y Acuña-Barrantes, H. (2015). La búsqueda de la raza perfecta. Ideas sobre procreación, vejez y eugenesia. Revista Eleuthera, volumen (13), 64-74. DOI: 10.17151/eleu.2015.13.5.

Gómez, J. (2006). Los hijos de la vergüenza, contracara del genocidio. Página 12. Recuperado de https://www.pagina12.com.ar/diario/sociedad/3-78310-2006$\underline{12-28 . h t m l}$

Poliakov, L. (2011). Brevario del odio. Barcelona, España: Editorial Cómplices.

Tendlarz, S. E. (2013). Shoa. Ética y cine journal, volumen (3), 83-88. Recuperado de http://journal.eticaycine.org/IMG/pdf/JEyC nov 2013 Tendlarz Shoa.pdf 